\title{
Design and construction of a simple Knudsen Effusion Mass Spectrometer (KEMS) system for vapour pressure measurements of low volatility organics
}

\author{
A. M. Booth ${ }^{1}$, T. Markus ${ }^{2}$, G. McFiggans ${ }^{1}$, C. J. Percival ${ }^{1}$, M. R. Mcgillen ${ }^{1}$, and D. O. Topping ${ }^{1}$ \\ ${ }^{1}$ School of Earth, Environmental and Atmospheric Science, University of Manchester, UK \\ ${ }^{2}$ Research Center Jülich, 52425 Jülich, Germany
}

Received: 20 February 2009 - Published in Atmos. Meas. Tech. Discuss.: 23 March 2009

Revised: 7 July 2009 - Accepted: 11 July 2009 - Published: 24 July 2009

\begin{abstract}
A design of and initial results from a Knudsen Effusion Mass Spectrometer (KEMS) are presented. The design was adapted from high temperature alloy studies with a view to using it to measure vapour pressures for low volatility organics. The system uses a temperature controlled cell with an effusive orifice. This produces a molecular beam which is sampled by a quadropole mass spectrometer with electron impact ionization calibrated to a known vapour pressure. We have determined $P_{(298 \mathrm{~K})}$ and $\Delta H_{\text {sub }}$ of the first 5 saturated straight chain dicarboxylic acids: $2.15 \pm 1.19 \times 10^{-2} \mathrm{~Pa}$ and $75 \pm 19 \mathrm{KJ} \mathrm{mol}^{-1}$ respectively for oxalic acid, $5.73 \pm 1.14 \times 10^{-4} \mathrm{~Pa}$ and $91 \pm 4 \mathrm{KJ} \mathrm{mol}^{-1}$ for Malonic acid, $1.13 \pm 0.47 \times 10^{-4} \mathrm{~Pa}$ and $93 \pm 6 \mathrm{KJ} \mathrm{mol}^{-1}$ for Succinic acid, $4.21 \pm 1.66 \times 10^{-4} \mathrm{~Pa}$ and $123 \pm 22 \mathrm{KJ} \mathrm{mol}^{-1}$ for Glutaric acid and $6.09 \pm 3.85 \times 10^{-6} \mathrm{~Pa}$ and $125 \pm 40 \mathrm{KJ} \mathrm{mol}^{-1}$ for Adipic acid.
\end{abstract}

\section{Introduction}

Knowledge of pure component vapour pressures is essential for calculations of gas/particle partitioning of compounds forming atmospheric aerosols. There are many methods of estimating vapour pressures but most of the experimental data collected to date has been for intermediate or high pressure compounds (and often measured at temperatures considerably above ambient) and the proportion of experimental data for low (less than $100 \mathrm{~Pa}$ ) vapour pressure compounds has been very small. Hence the datasets used for developing the estimation methods have reflected this bias in addition

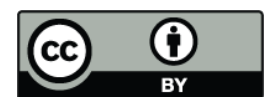

Correspondence to: A. M. Booth (alastair.booth@manchester.ac.uk) to the fact that components studied tend to have one or two functional groups at the most. The most intensively studied group are hydrocarbons for the oil industry with no functional groups. However, the vapour pressure of simple hydrocarbons are of less interest to the atmospheric community who are often concerned with multi-functional and heavily oxygenated hydrocarbons (Johnson et al., 2006; Yu et al., 1999). Therefore it is unsurprising that some of the estimation methods can give errors in vapour pressure of several orders of magnitude for multifunctional compounds at ambient temperatures (Makar, 2001; Camredon and Aumont, 2006; Pankow and Asher, 2008). The vapour pressure of all aerosol components are necessary to calculate the mass flux of condensing and evaporating compounds. Pure component vapour pressure data are lacking for the majority of multifunctional organic condensable compounds predicted to be formed from gas phase volatile organic carbon (VOC) oxidation (Johnson et al., 2005). Furthermore, the available predictive techniques for vapour pressures are largely unevaluated on multifunctional compounds. It is therefore necessary to evaluate such predictive techniques for selection of those most appropriate for atmospheric application and this requires a reliable method of determining vapour pressures of low volatility compounds at ambient temperatures.

Dicarboxylic acids are present in atmospheric aerosols and have been identified in multiple environments, and concentrations can vary significantly between regions (Bilde et al., 2003). They originate from photo-oxidation of biogenic and anthropogenic compounds but there is speculation about the exact origins and formation mechanisms. These vapour pressures have been previously studied by evaporation rates in Tandem Differential Mobility Analysers (TDMA) (Tao and McMurry, 1989; Bilde et al., 2003; Bilde and Pandis, 2001), Temperature Programmed Desorption (TPD) combined with

Published by Copernicus Publications on behalf of the European Geosciences Union. 
Proton Transfer Chemical Ionisation Mass Spectrometry (PT-CIMS) (Cappa et al., 2007; Chattopadhyay and Ziemann, 2005), and Knudsen mass loss effusion (Silva et al., 2001, 1999) and white light resonance spectroscopy (Zardini et al., 2006) and there are discrepancies between different measurement methods of up to two orders of magnitude for some compounds.

The dicarboxylic acids studied are solids at room temperature and pressure. In the atmosphere they can exists as subcooled liquids (Riipinen et al., 2007) making both the solid state and sub cooled liquid vapour pressures of interest. It is possible to correct between the solid and sub cooled state using the following equation (Prausnitz et al., 1986).

$\ln \frac{p_{l}}{p_{s}}=\frac{\Delta H_{\text {fus }}}{R T_{t}}\left(\frac{T_{t}}{T}-1\right)-\frac{\Delta c_{p, s l}}{R}\left(\frac{T_{t}}{T}-1\right)+\frac{\Delta c_{p, s l}}{R} \ln \frac{T_{t}}{T}$

where $p$ is the vapour pressure with the subscript s refering to the solid and $l$ to the liquid phase, $T_{t}$ is the triple point, $\Delta H_{\text {fus }}$ is the enthalpy of fusion in the melting point, and $\Delta c_{p, s l}$ denotes the change in heat capacity upon melting. This has been used by Riipinen to compare measure subcooled pressure with the solid state (Riipinen et al., 2006, 2007).

\section{Knudsen Effusion Mass Spectrometry}

Knudsen Effusion Mass Spectrometry (KEMS) is an established vapour pressure measurement technique capable of measuring vapour pressures from $10^{1}-10^{-8} \mathrm{~Pa}$ (e.g. for ceramic solutions and metal alloys at high temperature) (Shilov et al., 1997; Hilpert and Miller, 2004; Hilpert, 2001, 1991; Hastie, 1984). SOA components are likely to have vapour pressures around $10^{-4} \mathrm{~Pa}$ (Camredon and Aumont, 2006; Seinfeld and Pankow, 2003), measurable at ambient temperature, well inside the range measurable by KEMS. A temperature controlled Knudsen effusion cell, suitable for controlled generation of a molecular beam of the sample organic compounds is coupled to a vacuum chamber, and a quadrupole mass spectrometer to allow direct measurement of vapour pressure, analogous to the KEMS systems used to study the vapour pressure of ceramics (Bencze et al., 2006).

\section{Vacuum system}

The KEMS system is constructed primarily from "off-theshelf" standard conflat UHV components (Hositrad and Caburn), as shown in Fig. 1. A custom cold plate (PSP vacuum) was included to act as a beamstop if hot vapours are used. Copper gaskets are used for most seal except those for sample loading which are Viton. Separate pressure gauges and pumps are used on the upper and lower vacuums shown in Fig. 2.

The two chambers (Figs. 1 and 2) are connected via an all metal gate valve (VAT-valves). Each chamber is separately pumped by $701 \mathrm{~s}^{-1}$ pumping speed V-81-T turbo pumps

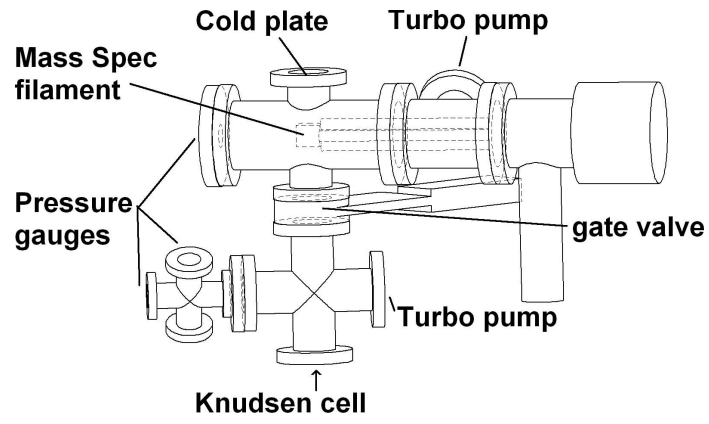

Fig. 1. Vacuum Chamber for KEMS system.

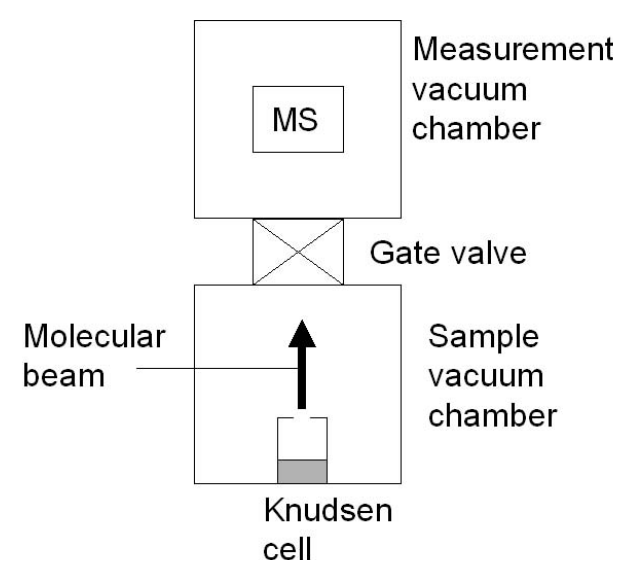

Fig. 2. Schematic of KEMS system.

(Varian) on CF 63 flanges with a SH-110 dry scroll backing pump. Pressure is measured using convectorr gauges (Varian) for atmospheric pressure down to $10^{-3} \mathrm{mbar}$, and IMG-100 inverted magnetron ion gauges for $<10^{-4} \mathrm{mbar}$ (Varian). Base pressure and pumping speeds are summarised in Table 1. Background mass spectrometer measurements showed common vacuum contamination $\mathrm{N}_{2}, \mathrm{O}_{2}, \mathrm{H}_{2} \mathrm{O}$, and small amounts of $\mathrm{CO}_{2}$. The KEMS chamber was baked to ensure there was no outgassing of volatile contaminents. Mass peaks from the samples drop to zero in between runs.

The mass spectrometer chamber is kept at $10^{-6}$ mbar or less with the ioniser left on to ensure different sample runs are directly comparable. During sample change the second chamber is isolated via the gate valve and vented to air. A Balzers-Pffeifer quadrupole mass spectrometer was used with a QMS 410 mass analyzer, a QMH 410 RF-box connected to a QMG 422 controller. Both faraday cup and secondary electron multiplier detection were used to measure ion intensities. Data collection and processing was performed using a PC running the Quadstar software package (INFICON-AG, 2005). 
Table 1. Pressures relevant to operation of the Knudsen Effusion Mass Spectrometer.

\begin{tabular}{lll}
\hline Pressures $(\mathrm{Pa})$ & $\begin{array}{l}\text { Measurement } \\
\text { Chamber }\end{array}$ & $\begin{array}{l}\text { Sample } \\
\text { Chamber }\end{array}$ \\
\hline Base Pressure & $10^{-5}$ & Atm to $10^{-5}$ \\
Operating Pressure & $10^{-3}-10^{-5}$ & $10^{-3}-10^{-5}$ \\
Pumping Speed & $701 \mathrm{~s}^{-1}$ & $701 \mathrm{~s}^{-1}$ \\
Ion Filament Max Pressure & $10^{-2}$ & $\mathrm{n} / \mathrm{a}$ \\
SEM Max Pressure & $10^{-3}$ & $\mathrm{n} / \mathrm{a}$ \\
\hline
\end{tabular}

\subsection{Knudsen cell}

The Knudsen cell was machined in-house (Fig. 3), and consists of a sample mount rigidly fixed onto a CF63 flange using torr-seal UHV compatible epoxy glue. Heating is provided by a coaxially mounted flexible polyimide heating element (Watlow) and measured with a K-type thermocouple. Samples are loaded into a removable cell and a lid is fixed onto with a champfered effusion orifice. Previous workers have found a chamfered effusion orifice ensures that the hole is formed as a "knife edge" helping it act as a 2-D hole rather than a cylinder. Effusion orifices were made with hole sizes of $200 \mu \mathrm{m}, 1 \mathrm{~mm}, 2 \mathrm{~mm}$ and $3 \mathrm{~mm}$. Table 2 shows the mean free paths of 3 compounds with the Knudsen numbers using the different hole sizes. Ferrocene, the highest pressure calibration compound, Oxalic acid, the lowest pressure calibration compound and Adipic acid, the lowest pressure compound measured.

\subsection{Measurements of calibration compounds}

Pressure and thermodynamic data is determined by measuring the total ion signal and comparing this with a sample of known vapour pressure. The Knudsen orifice is small enough that effusive flow occurs from the cell without disturbing the thermodynamic equilibrium. This produces a molecular beam with an intensity proportional to the vapour pressure in the cell above the sample. The system can be used to determine partial pressures of mixed systems. The pressure of the $i$-th component in the KEMS instrument $P_{i}$ in Pascals, is given by:

$P_{i}=\frac{k I_{i} T}{\sigma_{i}}$

where $I_{i}$ is the ion intensity measured in the mass spectrometer, $\sigma_{i}$ is the ionisation cross section and $T$ is the temperature of the Knudsen cell in Kelvin. And $k$ is the machine constant which incorporates information on the geometry of the system, clausing factor of the effusion orifice and any other correction factors, $k$ is determined by using the reference samples. $\sigma_{i}$ is calculated by summing the ionisation
Table 2. Mean free paths and Knudsen numbers $\left(K_{n}\right)$ of 3 compounds; Ferrocene, Oxalic acid and Adipic acid.

\begin{tabular}{llllll}
\hline Compound & Mean & $K_{n}$, & $K_{n}$, & $K_{n}$, & $\begin{array}{l}K_{n}, \\
1 \mathrm{~mm} \\
\end{array}$ \\
& $\begin{array}{l}\text { Free } \\
\text { Path } \\
(\mathrm{mm})\end{array}$ & $\begin{array}{l}0.2 \mathrm{~mm} \\
\text { hole } \\
\text { size }\end{array}$ & $\begin{array}{l}1 \mathrm{~mm} \\
\text { hole } \\
\text { size }\end{array}$ & $\begin{array}{l}\text { hole } \\
\text { size }\end{array}$ & $\begin{array}{l}\text { hole } \\
\text { size }\end{array}$ \\
\hline Adipic acid & 730000 & 3638000 & 730000 & 364000 & 243000 \\
Oxalic acid & 180 & 910 & 180 & 90 & 60 \\
Ferrocene & 3.6 & 18 & 3.6 & 1.8 & 1.2 \\
\hline
\end{tabular}

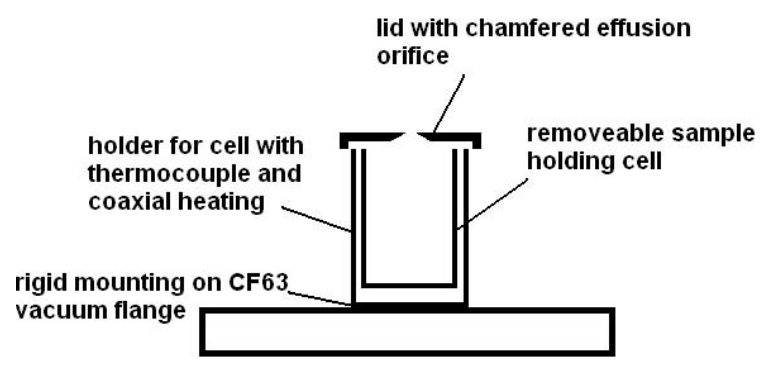

Fig. 3. Schematic of Knudsen cell.

cross section from each atom in the molecule at the ionisation energy $(70 \mathrm{eV})$ (Hilpert, 2001). The hole size directly impacts on $k$ and should be chosen so that the ratio of mean free path to hole size (Knudsen number) is $\geq 10$ (Table 2). A further consideration for the KEMS system is that the minimum hole size is limited by the detection limit of the mass spectrometer, and the maximum hole size should not be high enough to burn out the electron impact filament or secondary electron multiplier (SEM).

Once the vapour pressure, $P$, has been determined at a number of different temperatures further thermodynamic data can be obtained using the Clausius-Clapeyron equation (Hilpert, 2001).

$\ln P=\frac{\Delta H_{\mathrm{sub}}}{R T}+\frac{\Delta S_{\mathrm{sub}}}{R}$

where $T$ is the temperature, $R$ is the ideal gas constant and $\Delta H_{\text {sub }}$ and $\Delta S_{\text {sub }}$ are the enthalpies and entropies of sublimation respectively.

\section{Results}

Knudsen Effusion Mass Spectrometry has to use a calibration compound in order to determine $\mathrm{k}$ and hence provide absolute pressure measurements. Three compounds that had previously been measured by Knudsen mass-loss effusion, an absolute pressure technique, were chosen as reference samples. Ferrocene (Jacobs et al., 1983), Benzophenone (Kruif et al., 1983) and Diphenlyethane (Van Ekeren et al., 1982) each have vapour pressures in the range $1-0.1 \mathrm{~Pa}$ at $298 \mathrm{~K}$ 
which is high enough to have reasonable mass-loss data but low enough to provide a calibration for the low volatility compounds the KEMS was constructed for. Table 3 shows determinations of the vapour pressures of the each of the 3 reference compounds using the literature values of the other 2.

Spectra were measured at 5 degree temperature increments. The sample was left to equilibrate for $10 \mathrm{~min}$ at each temperature step. This was based on how long it took the mass spectrometer signal to stop increasing after a temperature step, plus a wide margin, to ensure consistent comparable temperatures were obtained. Ionisation cross sections were calculated by summing up the individual electron impact cross sections from each atom in the molecule (Hilpert, 2001) using values from the NIST electron impact database.

We have studied the $\mathrm{C}_{2}-\mathrm{C}_{6}$ straight chain saturated dicarboxylic acids: Oxalic, Malonic, Succinic, Glutaric and Adipic acids. Samples were obtained from Sigma Aldrich with purities of $99 \%$ or higher. Approximately $0.1 \mathrm{~g}$ was placed in the K-cell with no further preparation. Oxalic acid was measured using the $200 \mu \mathrm{m}, 1 \mathrm{~mm}$ and $3 \mathrm{~mm}$ holes. The other dicaboxylic acids had a much lower vapour pressure and were only studied using the $3 \mathrm{~mm}$ hole as a result of small signal-to-noise when using the smaller holes in conjunction with the Faraday Cup detection. However, when using the SEM there is an enhancement in signal-to-noise by a factor of $\geq 10$ which enabled the dicarboxylic acid vapour pressures to be quantified using the $2 \mathrm{~mm}$ hole. Figure 4 shows a mass spectrometer trace of Malonic acid at $313 \mathrm{~K}$ for comparison of the signal to noise for Faraday Cup and SEM detection. Errors were determined by the standard deviation of repeated measurements of oxalic acid using all 3 reference compounds. We have determined a $P_{(298 \mathrm{~K})}$ of $2.15 \pm 1.19 \times 10^{-2} \mathrm{~Pa}$ and enthalpies and entropies of sublimation of $75 \pm 19 \mathrm{KJ} \mathrm{mol}^{-1}$ and $213 \pm 55 \mathrm{~J} \mathrm{~mol}^{-1} \mathrm{~K}^{-1}$ for oxalic acid (Fig. 5), which is comparable to the variation in the calibration compounds.

The remaining dicarboxylic acids had much lower volatilities, requiring the $3 \mathrm{~mm}$ hole size to be used with the Faraday Cup detector to increase the mass spectrometer signal. Using the previous calibration compounds was impossible as a result of the Knudsen number being too low for effusive flow (Table 2). Additionally, such a large hole would result in too high a pressure in the ionization region of the KEMS, which would result in a risk of the ioniser burning out. The data shown in Table 4 is the average of 3 independent runs using literature (de Wit et al., 1982) values for oxalic acid as the calibration compound with either the Faraday Cup detector or the SEM detector, and 1 run which used our malonic acid values as the calibration with the SEM detector. The reported errors are the standard deviation over 4 runs.

Random errors arise from variation in the mass spectrometer signal (ioniser, and SEM/Faraday Cup detector). The error for oxalic acid is high as a result of the variation in the 3 calibration compounds used for its determination (Table 3 ).
Table 3. Vapour pressure (298 K), Enthalpy of sublimation and Entropy of sublimation of the calibration compounds. Literature values 1,2,3 (Van Ekeren et al., 1982; Jacobs et al., 1983; Kruif et al., 1983) are shown. The values determined using the KEMS are also reported to illustrate internal consistency between calibration compounds. The compound in brackets denotes the calibration compound used to determine that value.

\begin{tabular}{|c|c|c|c|}
\hline Compound & $\begin{array}{l}P_{(298 \mathrm{~K})} \\
(\mathrm{Pa})\end{array}$ & $\begin{array}{l}\Delta H_{\text {sub }} \\
\left(\mathrm{kJ} \mathrm{mol}^{-1}\right)\end{array}$ & $\begin{array}{l}\Delta S_{\mathrm{sub}} \\
\left(\mathrm{J} \mathrm{mol}^{-1} \mathrm{~K}^{-1}\right)\end{array}$ \\
\hline Benzophenone $^{1}$ & 0.162 & 67.6 & 212 \\
\hline $\begin{array}{l}\text { Benzophenone } \\
\text { (Ferrocene) }\end{array}$ & 0.135 & 74.2 & 232 \\
\hline $\begin{array}{l}\text { Benzophenone } \\
\text { (Diphenylethane) }\end{array}$ & 0.101 & 87.3 & 274 \\
\hline Ferrocene $^{2}$ & 0.760 & 90.0 & 300 \\
\hline $\begin{array}{l}\text { Ferrocene } \\
\text { (Benzophenone) }\end{array}$ & 1.022 & 76.9 & 258 \\
\hline $\begin{array}{l}\text { Ferrocene } \\
\text { (Diphenylethane) }\end{array}$ & 1.226 & 70.3 & 238 \\
\hline Diphenylethane ${ }^{3}$ & 0.497 & 93.7 & 309 \\
\hline $\begin{array}{l}\text { Diphenylethane } \\
\text { (Benzophenone) }\end{array}$ & $\begin{array}{l}0.491 \\
0.371\end{array}$ & 106.8 & 350 \\
\hline $\begin{array}{l}\text { Diphenylethane } \\
\text { (Ferrocene) }\end{array}$ & 0.598 & 87.1 & 288 \\
\hline
\end{tabular}

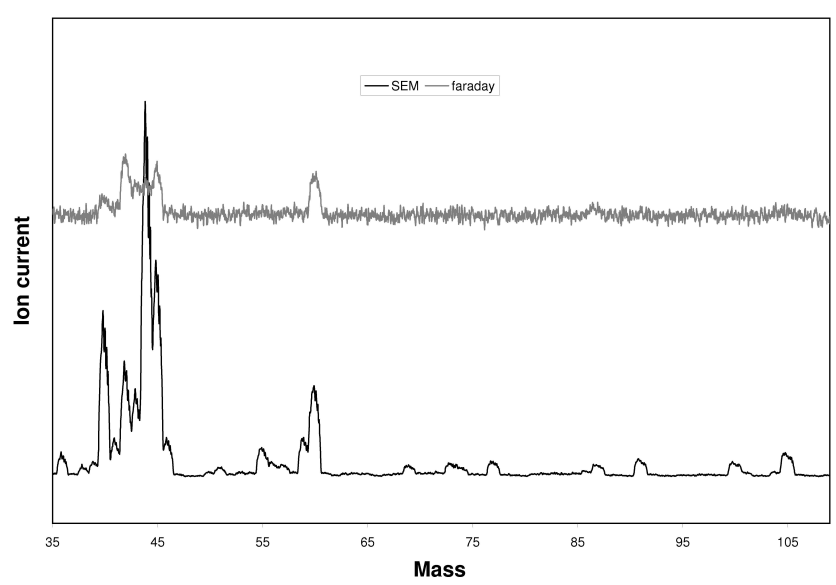

Fig. 4. Mass spectrometer traces for malonic acid at $313 \mathrm{~K}$ using faraday and SEM detection.

The adipic acid has a higher error because of its lower pressure, resulting in decreased signal to noise ratio. Systematic errors can be introduced by the choice of reference compound as measurements are relative to this and from calculation of the ionisation cross section. In all cases, the accommodation coefficient is assumed to be identical between samples. Such an assumption may introduce unquantifiable errors, but it is expected that they are minimized by appropriate choice of similar reference and sample compounds. 
Table 4. Vapour pressure, Enthalpy and Entropy of sublimation of the dicarboxylic acids.

\begin{tabular}{llllll}
\hline Acid & $\begin{array}{l}\text { Averaged } P_{(298 \mathrm{~K})} \\
(\mathrm{Pa})\end{array}$ & $\begin{array}{l}P_{(298 \mathrm{~K})} \\
2 \mathrm{~mm} \mathrm{hole}\end{array}$ & $\begin{array}{l}P_{(298 \mathrm{~K})} \\
3 \mathrm{~mm} \mathrm{hole}\end{array}$ & $\begin{array}{l}\Delta H_{\text {sub }} \\
\left(\mathrm{kJ} \mathrm{mol}^{-1}\right)\end{array}$ & $\begin{array}{l}\Delta S_{\text {sub }} \\
\left(\mathrm{J} \mathrm{mol}^{-1} \mathrm{~K}^{-1}\right)\end{array}$ \\
\hline Malonic & $5.73 \pm 1.14 \times 10^{-4}$ & $4.61 \times 10^{-4}$ & $6.29 \times 10^{-4}$ & $92 \pm 4$ & $238 \pm 29$ \\
Succinic & $1.13 \pm 0.47 \times 10^{-4}$ & $9.49 \times 10^{-5}$ & $1.32 \times 10^{-4}$ & $93 \pm 6$ & $222 \pm 17$ \\
Glutaric & $4.21 \pm 1.66 \times 10^{-4}$ & $5.15 \times 10^{-4}$ & $4.21 \times 10^{-4}$ & $123 \pm 22$ & $208 \pm 74$ \\
Adipic & $3.28 \pm 3.85 \times 10^{-6}$ & $6.09 \times 10^{-6}$ & $1.52 \times 10^{-6}$ & $119 \pm 26$ & $231 \pm 3$ \\
\hline
\end{tabular}

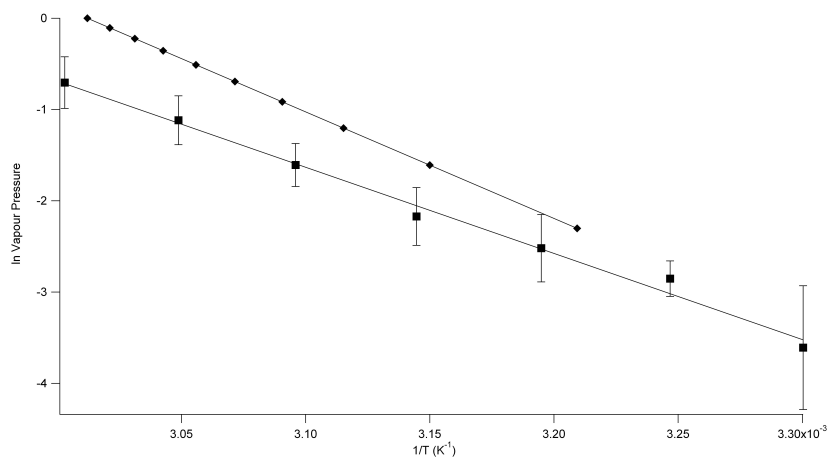

Fig. 5. In vapour pressure against $1 /$ Temperature for oxalic acid. This work denoted (ם) and the overall trend from De Wit $(\diamond)$.

KEMS directly measures the steady state vapour pressure but the equilibrium vapour pressure is desired. Corrections between steady state and equilibrium can be applied ( $\mathrm{Li}$ et al., 2003; Silva and Monte, 1990), but if the Knudsen number is high enough then effusing gas does not significantly disturb the equilibrium in the cell ( $\mathrm{Li}$ et al., 2003; Hilpert, 1991, 2001). The Knudsen number can be chosen such that the steady state pressure measured is as close as possible to equilibrium conditions (negligible perturbation of condensation/evaporation equilibrium). There is no systematic difference between hole size for our dicarboxylic acid determinations so the steady state vapour pressure is indistinguishably close to the equilibrium vapour pressure for our dicarboxylic acid determinations in Table 4.

Figures 6 and 7 show the results for the vapour pressure and enthalpy of sublimation respectively for the first 5 dicarboxylic acids obtained in this work. Also shown are comparable data from other workers using different vapour pressure techniques, TDMA (Bilde et al., 2003; Tao and McMurry, 1989), PT-CIMS (Cappa et al., 2007), white light resonance spectroscopy (Zardini et al., 2006; Zardini and Krieger, 2009) and Knudsen mass loss (Silva et al., 2001).

\section{Discussion}

The results show the distinct odd-even effect well-known in the homologous straight chain dicarboxylic acids. The data presented in this work tends to give higher values than those

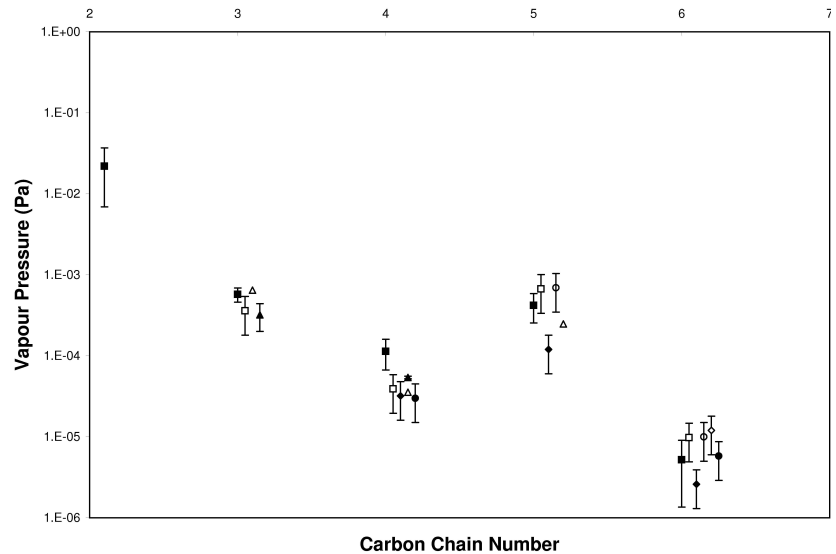

Fig. 6. Vapour pressures at $298 \mathrm{~K}$. This work (ם), Bilde (2003) $(\square)$, Cappa et al. (2007) (\$), Chattopadhyay and Ziemann (2005) $(\diamond)$, da Silva (1999) $(\triangle)$, Davies and Thomas (1960) (•), Tao and McMurry (1989) (o) and Zardini $(2006,2009)$ ( $\mathbf{\Delta})$.

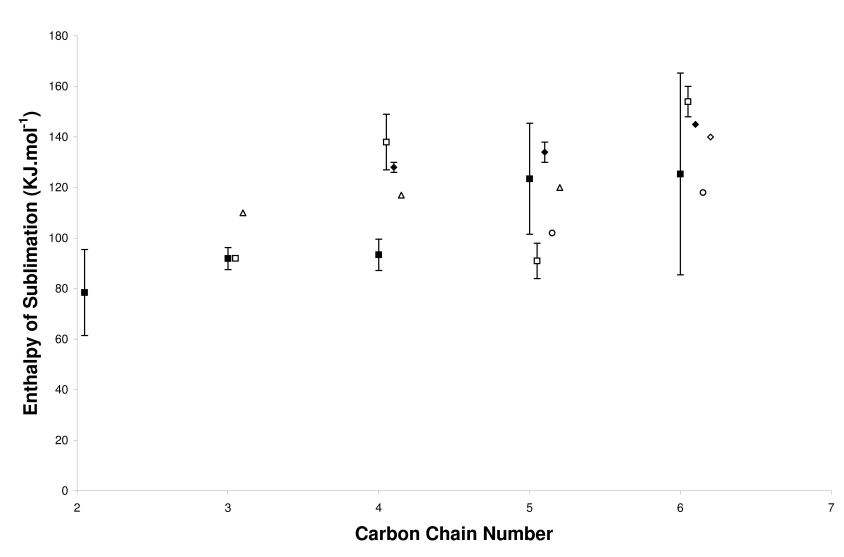

Fig. 7. Enthalpies of sublimation: This work ( $\square)$, Bilde (2003) ( $\square$ ), Cappa et al. (2007) ( ) Chattopadhyay and Ziemann (2005) ( $\diamond)$, da Silva (1999) $(\triangle)$ and Tao and McMurry (1989) (o).

reported by Bilde et al. (2003) and Tao and McMurry (1989) for malonic and succinic acid and lower for glutaric and adipic acid. The (Cappa et al., 2007) results are at the lower end of reported values. The Enthalpies of sublimation however show considerable differences between the different methods used, this wide variance has also been reported for the higher carbon chain length dicarboxylic acids. Analogous to the measurement of reaction kinetics, the spread of reported experimental values at temperatures other than ambient increases. This probably is as a result of small discrepancies in the $P_{(298 \mathrm{~K})}$ being magnified as the temperature increases affecting the enthalpies.

Bilde et al. (2003) and Tao and McMurry (1989) both used TDMA to study evaporation rates of aerosol particles of dicarboxylic acids, rather than bulk samples as in this work. Bilde et al. (2003) and Tao and McMurry (1989) method requires an understanding of the aerosol flow with the TDMA 
and a model of the evaporation of a particle within the flow tube. The assumptions necessary for this may explain some of the differences between the results obtained in this study. They both state that a major source of errors in their measurement are uncertainties in the theory of mass transfer from transition regime particles, and the presence of unevaporated water within the aerosol particle. Accomodation coefficient discrepancies could also account for this. Even so the results of this work are in good agreement (within $3 \sigma$ ) for $P_{(298 \mathrm{~K})}$. Silva et al. (2001) used Knudsen mass loss effusion, similar to the KEMS technique presented in this paper but as a result of the low volatility of the sample and the lack of sensitivity compared to the KEMS technique the data was obtained at much higher temperatures. This was to ensure sufficient sample was sublimed to detect using a balance. Data was extrapolated to obtain results at $298 \mathrm{~K}$. Cappa et al. (2007) used PT-CIMS to observe the evaporation rates of aerosol samples collected on a cold plate. Their TPD experiments involved a preheating stage to drive off volatile impurities in the sample, however significant fractions of the sample were lost which may inadvertently effect results explaining the lower $P_{(298 \mathrm{~K})}$ compared to the $P_{(298 \mathrm{~K})}$ presented in this work.

Whereas the odd-even effect in vapour pressures is well known, there is no agreement on its existence in enthalpy measurements. Bilde et al. (2003) see an odd-even effect in enthalpy which Cappa et al. (2007) and Silva et al. (2001) do not. As a result of the large enthalpy errors for glutaric and adipic acids, it is not possible to say for certain that an oddeven effect in enthalpy is observed in this work. Indeed, if one is observed it is reversed compared to Bilde et al. (2003). However, within experimental error as in the work of Cappa et al. (2007) we do not observe an odd-even effect in enthalpy.

\section{Conclusions}

We have presented the design of a Knudsen effusion mass spectrometer for the measurement of the sort of low volatility organics which will partition in the atmosphere into the aerosol phase. We have also measured homologous straight chain dicarboxylic acids and compared the results with other techniques. KEMS provides a number of advantages over other methods, the use of bulk samples eliminates the needs for simplifying assumptions required when using aerosol based techniques, the only limiting requirement is a sample of known vapour pressure to act as a calibration. The high sensitivity of the mass spectrometer enables data to be obtained around ambient atmospheric temperatures unlike Knudsen mass-loss where temperatures must be significantly elevated for very low volatility samples. The KEMS system presented in this paper can be used to study even lower volatility systems by increasing the orifice size, raising the temperature or improving the sensitivity of the mass spectrometer. Unfortunately water is too volatile for the KEMS system which results in an inability to study aqueous mixtures such as those that may be present in real atmospheric aerosols. This is a major strength of TDMA type measurements (Riipinen et al., 2006, 2007).

Acknowledgements. The authors gratefully acknowledge the financial support of NERC research grant reference number NE/E018181/1.

Edited by: A. S. H. Prévôt

\section{References}

Bencze, L., Markus, T., Dash, S., Raj, D. D., Kath, D., Oates, W. A., Loser, W., and Hilpert, K.: Thermodynamic Properties of B2AlFeNi Alloys. Part 1: Investigation by Knudsen Effusion Mass Spectrometry, Metall. Mater. Trans. A, 37, p. 3171, 2006.

Bilde, M., and Pandis, S.: Evaporation Rates and Vapor Pressures of Individual Aerosol Species Formed in the Atmospheric Oxidation of alpha- and beta-Pinene, Environ. Sci. Technol., 35, p. 3344, 2001.

Bilde, M., Svenningsson, B., Monster, J., and Rosenorn, T.: EvenOdd Alternation of Evaporation Rates and Vapor Pressures of C3-C9 Dicarboxylic Acid Aerosols, Environ. Sci. Technol., 37(7), p. 1371, 2003.

Camredon, M. and Aumont, B.: Assessment of vapor pressure estimation methods for secondary organic aerosol modeling, Atmos. Environ., 40, 2105-2116, 2006.

Cappa, C., Lovejoy, E., and Ravishankara, A.: Determination of Evaporation Rates and Vapor Pressures of Very Low Volatility Compounds: A Study of the C4-C10 and C12 Dicarboxylic Acids, J. Phys. Chem. A, 111(16), p. 3099, 2007.

Chattopadhyay, S. and Ziemann, P.: Vapor Pressures of Substituted and Unsubstituted Monocarboxylic and Dicarboxylic Acids Measured Using an Improved Thermal Desorption Particle Beam Mass Spectrometry Method, Aerosol Sci. Tech., 39, 1085-1100, 2005.

Davies, M. and Thomas, G.: The lattice energies, infra-red spectra, and possible cyclization of some dicarboxylic acids, T. Faraday Soc., 56, p. 185, 1960.

de Wit, H. G. M., Bouwstra, J. A., Blok, J. G., and Kruif, C. G. D.: Vapor pressures and lattice energies of oxalic acid, mesotartaric acid, phloroglucinol, myoinositol, and their hydrates, J. Chem. Phys., 78, 1470, 1982.

Hastie, J.: New techniques and opportunities in high temperature mass spectrometry, Pure Appl. Chem., 56, p. 1583, 1984.

Hilpert, K.: High-temperature Mass Spectrometry in Materials Research, Rapid Temperature Assembly for a Quadrupole QMG420 Mass Spectrometer, Rapid Commun. Mass Sp., 5, p. 175, 1991.

Hilpert, K.: Potential of mass spectrometry for the analysis of inorganic high-temperature vapors, Fresen. J. Anal. Chem., 370, p. 471, 2001.

Hilpert, K. and Miller, M.: Determination of the thermodynamic activities of $\mathrm{NaBr}$ and $\mathrm{DyBr}_{3}$ in the phases of the $\mathrm{NaBr}-\mathrm{DyBr} \mathrm{r}_{3}$ system at $863 \mathrm{~K}$ by Knudsen effusion mass spectrometry, J. Alloy. Compd., 379, p. 1, 2004. 
Jacobs, M., Van Ekeren, P., and Kruif, C. G. D.: The vapour pressure and enthalpy of sublimation of ferrocence, J. Chem. Thermodyn., 15, p. 619, 1983.

Johnson, D., Jenkin, M. E., Wirtz, K., and Martin-Reviejo, M.: Simulating the Formation of Seconday Organic Aersol from the Photooxidation of Aromatic Hydrocarbons, Environ. Chem., 2, 3548, 2005.

Johnson, D., Utembe, S. R., and Jenkin, M. E.: Simulating the detailed chemical composition of secondary organic aerosol formed on a regional scale during the TORCH 2003 campaign in the southern UK, Atmos. Chem. Phys., 6, 419-431, 2006, http://www.atmos-chem-phys.net/6/419/2006/.

Kruif, C. G. D., Miltenburg, J. C. V., and Blok, J.: Molar heat capacities and vapour pressures of solid and liquid benzophenone, J. Chem. Thermodyn., 15, p. 129, 1983.

Li, X., Shibata, E., Kasai, E., and Nakamura, T.: The Construction and Testing of a New Apparatus with Knudsen Effusion Method Designed for Low Vapor Pressure Measurements of POPs, Tohoku Daigaku Tagen Busshitsu Kagaku Kenkyusho Sozai Kogaku Kenkyu Iho, 58, 29-35, 2003.

Makar, P. A.: The estimation of organic gas vapour pressure, Atmos. Environ., 35, 961-974, 2001.

Pankow, J. F. and Asher, W. E.: SIMPOL.1: a simple group contribution method for predicting vapor pressures and enthalpies of vaporization of multifunctional organic compounds, Atmos. Chem. Phys., 8, 2773-2796, 2008, http://www.atmos-chem-phys.net/8/2773/2008/.

Prausnitz, J. M., Lichtenhaler, R. N., and de Azevedo, E. G.: Molecular Thermodynamics of Fluid-phase Equilibria, Prentice-Hall Inc, New Jersey, 1986

Riipinen, I., Svenningsson, B., Bilde, M., Gamana, A., Lehtinenc, K. E. J., and Kulmalaa, M.: A method for determining thermophysical properties of organic material in aqueous solutions: Succinic acid, Atmos. Res., 82, 579-590, 2006.

Riipinen, I., Koponen, I., Bilde, M., Hienola, A., and Kulmala, M.: Evaporation Rates and Saturation Vapour Pressures of C3-C6 Dicarboxylic Acids, in: Nucleation and Atmospheric Aerosols, edited by: O'Dowd, C. D. and Wagner, P. E., Springer, Galway, Ireland, 920-923, 2007.
Seinfeld, J. H. and Pankow, J. F.: Organic atmospheric particulate material, Annu. Rev. Phys. Chem $\dot{\iota}$, 54, 121-140, 2003.

Shilov, A. L., Holappa, L. E., and Stolyarova, V. L.: A Knudsen Effusion High Temperature Assembly for a Quadrupole QMG420 Mass Spectrometer, Rapid Commun. Mass Sp., 11, p. 1425 , 1997.

Silva, M. R. D. and Monte, M.: The Construction, Testing and Use of a New Knudsen Effusion Apparatus, Thermochim. Acta, 171, p. 169,1990

Silva, M. R. D., Monte, M., and Ribeiro, J.: Vapour pressures and the enthalpies and entropies of sublimation of five dicarboxylic acids, J. Chem. Thermodyn., 31, p. 1093, 1999.

Silva, M. R. D., Monte, M., and Ribeiro, J.: Thermodynamic study on the sublimation of succinic acid and of methyl- and dimethylsubstituted succinic and glutaric acids, J. Chem. Thermodyn., 33, p. 23, 2001.

Tao, Y. and McMurry, P.: Vapor Pressures and Surface Free Energies of C14-C18 Monocarboxylic Acids and C5 and C6 Dicarboxylic Acids, Environ. Sci. Technol., 23, p. 1519, 1989.

Van Ekeren, P., Jacobs, M., Offringa, J., and Kruif, C. G D.: Vapour-pressure measurements on trans-diphenylethene and naphthalene using a spinning-rotor friction gauge, J. Chem. Thermodyn., 15, p. 409, 1982.

Yu, J., Cocker III, D. R., Griffin, R. J., Flagan, R. C., and Seinfeld, J. H.: Gas-Phase Ozone Oxidation of Monoterpenes: Gaseous and Particulate Products, J. Atmos. Chem., 34, 207-258, 1999.

Zardini, A. A., Krieger, U. K., and Marcolli, C.: White light Mie resonance spectroscopy used to measure very low vapor pressures of substances in aqueous solution aerosol particles, Opt. Express, 14(15), 6951-6962, 2006.

Zardini, A. A. and Krieger, U. K.: Evaporation kinetics of a nonspherical, levitated aerosol particle using optical resonance spectroscopy for precision sizing, Opt. Express, 17(6), 4659-4669, 2009. 